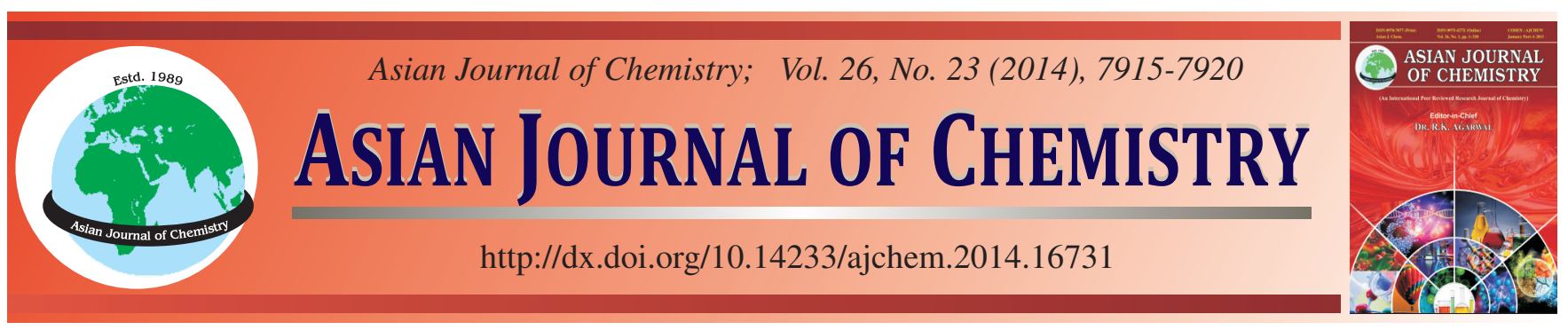

\title{
Analysis on Structural Changes of Poly(vinyl acetate) by Two-Dimensional Correlation Infrared Spectroscopy
}

\author{
Yong Huang ${ }^{1,2}$, TaO Zhou ${ }^{1, *}$, Junhong Liu ${ }^{2}$ and Aimin Zhang ${ }^{1, *}$
}

${ }^{1}$ State Key Laboratory of Polymer Materials Engineering of China, Polymer Research Institute, Sichuan University, Chengdu 610065, P.R. China ${ }^{2}$ Sichuan Chemical and Technology School, Luzhou 646005, Sichuan Province, P.R. China

*Corresponding authors: Fax: +86 28 85402465; Tel: +86 28 85405868; E-mail: zhoutaopoly@ scu.edu.cn; amzhang215@ vip.sina.com

\begin{abstract}
Poly(vinyl acetate) (PVAc) was investigated using generalized two-dimensional infrared (2D IR) correlation spectroscopy and movingwindow two-dimensional spectroscopy (MW2D) with temperature raising from 10 to $200{ }^{\circ} \mathrm{C}$. The glass transition of poly(vinyl acetate) determined by MW2D measurement is $52^{\circ} \mathrm{C}$. Four types of $\mathrm{C}=\mathrm{O}$ stretching modes in different phase were clearly detected by asynchronous spectrum as poly(vinyl acetate) transfers from solid phase to liquid phase. The bands at $1762 \mathrm{~cm}^{-1}$ arise from free bonded $\mathrm{C}=\mathrm{O}$ groups in liquid phase and $1753 \mathrm{~cm}^{-1}$ attributes to the free or non-interaction $\mathrm{C}=\mathrm{O}$ groups in solid phase. The bands at 1733 and $1724 \mathrm{~cm}^{-1}$ attribute to the $\mathrm{C}=\mathrm{O}$ groups involved in the $\mathrm{C}=\mathrm{O}$ and $\mathrm{OH}$ interactions in liquid phase and solid phase, respectively. The sequential order of bands changes is also discussed. In addition, seven bands are identified at 3020, 2990, 2980, 2972, 2957, 2903 and $2851 \mathrm{~cm}^{-1}$ by 2D correlation spectra. The bands at 2990, 2980 and $2972 \mathrm{~cm}^{-1}$ are assigned to $\mathrm{CH}_{2}$ groups. The bands at 2957, $2851 \mathrm{~cm}^{-1}$ and $2903 \mathrm{~cm}^{-1}$ attribute to $\mathrm{O}-\mathrm{CH}_{3}$ (ester group) asymmetric stretching, symmetric stretching and $\mathrm{CH}$ asymmetric stretching vibrations, respectively. With the temperature increasing, $\mathrm{CH}_{3}$ or $\mathrm{CH}$ group responds firstly and then $\mathrm{CH}_{2}$ group, after that $\mathrm{HC}=\mathrm{CH}$ group follows, which denotes the side chain takes place prior to major chain.
\end{abstract}

Keywords: Poly(vinyl acetate), Moving-window two-dimensional correlation infrared spectroscopy, 2D IR correlation spectroscopy.

\section{INTRODUCTION}

After more than two decades, polymer blends have been widely studied because the structural and some physical properties of the modified polymers can be over the constituent polymer. However, most polymer blends are immiscible due to the absence of specific interaction and entropy of mixing of two polymers is negligibly small. As a result, many investigations have been carried out with emphasis on hydrogen bonds as miscibility enhancers ${ }^{1-14}$. In order to investigate and elucidate the hydrogen bonds in polymer blends, the blends of poly(vinyl acetate) as the typical proton-acceptor material and other proton-donor polymers are often discussed ${ }^{1-5}$. The miscibility of poly(vinyl acetate) with polycaprolactone (PCL) was studied using DSC and a single transition temperature was observed for the complete range ${ }^{4}$. The miscibility of poly(vinyl acetate) and atactic poly(epichlorohydrin) was also investigated by fourier transform infrared spectroscopy (FT-IR) and suggests that the carbonyl groups of poly(vinyl acetate) may not involve in a hydrogen-bonding interaction with $\alpha$-hydrogen of atactic poly(epichlorohydrin) ${ }^{1}$. Because of the formation of hydrogen bonding between hydroxyl groups of phenolic resin and carbonyl groups of poly(vinyl acetate), the blend of phenolic resin and poly (vinly acetate) is miscible in the amorphous over entire composition ${ }^{3}$.

Poly(vinyl acetate) is also used for the preparing solid polymer electrolytes ${ }^{15,16}$. By the results of the peak shift in the IR region of $\mathrm{C}-\mathrm{O}-\mathrm{C}$ and $\mathrm{C}=\mathrm{O}$ in poly(vinyl acetate), it confirms that both $\mathrm{C}-\mathrm{O}-\mathrm{C}$ and $\mathrm{C}=\mathrm{O}$ groups have an important interaction to the lithium cations and $\mathrm{ClO}_{4}{ }^{-}$anions ${ }^{15}$.

By the FTIR spectra of pure poly(vinyl acetate) (PVAc) and $\mathrm{PVAc} / \mathrm{SiO}_{2}$ composites, it is believed that the hydrogen bonds between the silanol groups of the silica particles and the hydroxyl groups (not the carbonyl groups) of poly(vinyl acetate) played a dominating role in the formation of stable PVAc/ $/ \mathrm{SiO}_{2}$ colloid $^{17}$.

However, little attention has been paid to chemical structure and structure changes of poly(vinyl acetate). In order to further elucidate the transformation process of hydrogen bonding of phenolic resin and poly(vinyl acetate) blend as temperature rises, our groups tried to use temperature-dependent infrared spectra analysis to study. However, the information that we got from poly(vinyl acetate) with the temperature increasing by moving-window 2D (MW2D) and 2D correlation spectroscopy (2D IR) is more complex than our expected. It is well known that the chemical structure of polymer will affect 
the miscibility, phase behaviour and some physical properties in polymer blends. So it is necessary to get more details on the chemical structure and structure changes of poly(vinyl acetate) with temperature increasing.

Fourier transform infrared spectroscopy (FT-IR) has been proved to be an excellent tool of studying the hydrogen bond and structure in different polymers. However, the obtained IR spectra are complicated because they contain many overlapping bands involved with the different species of hydrogen bonding. The application of generalized two-dimensional correlation infrared spectroscopy analysis ${ }^{18,19}$ has been proved extremely useful in revealing these subtle responses that are hidden in the complex dynamic infrared data. Asynchronous 2D spectra are very powerful in differentiating highly overlapped bands that vary out of phase under the external perturbation $^{20}$. The signs of synchronous and asynchronous cross peaks indicate the sequential order of the events taking place under the applied perturbation ${ }^{21,22}$.

Moving-window 2D (MW2D) correlation spectroscopy, which was proposed first by Thomas and Richardson in $2000^{23}$, is a powerful method to visualize spectral correlation variation along both spectral variable and perturbation variable axes. Our groups have successfully applied the MW2D correlation analysis to investigate some complex molecular chain movements and transitions of $\mathrm{SEBS}^{24}$.

By the analysis of IR spectra in the $\mathrm{C}=\mathrm{O}$ stretching band region, the crystallization and melting behaviour of crystalline polymer have been successfully studied. It has demonstrated that $\mathrm{C}=\mathrm{O}$ groups in crystalline polymers will spilt into two or three even more bands ${ }^{25-29}$. However, few studies have pay attention to the types of $\mathrm{C}=\mathrm{O}$ in amorphous polymer as temperature increases. Poly(vinyl acetate) is typical amorphous polymer, which is also often chosen as a model low-molecular polymer for structural relaxation studies. The experimental methods for these studies are based on differential scanning calorimetry measurements (DSC), mercury dilatometry ${ }^{30-38}$. However, most of these ways to study structural relaxation are concerned with some macroscopic property (volume, enthalpy and refraction index) departing during continuing cooling.

In the present study, the aim is to elucidate the structure and structural changes of poly(vinyl acetate) by two-dimensional correlation infrared spectroscopy. Temperature-depended IR of poly(vinyl acetate), a type amorphous polymer, has never been analyzed in detail. Therefore, result of the present study is not only important for the study of amorphous polymers but also for the further study of blends of poly(vinyl acetate).

\section{EXPERIMENTAL}

Poly(vinyl acetate) used in this study was obtained from Sinopharm Chemical Reagent Co., Ltd. Poly(vinyl acetate) was directly used in experiment without further purification.

A film of poly(vinyl acetate) sample was prepared by spreading on one side of a $\mathrm{KBr}$ disk via solvent casting. The solution was fully dissolved in THF solution. The KBr disk together with poly(vinyl acetate) was dried in a vacuum-dried oven at $80^{\circ} \mathrm{C}$ for $8 \mathrm{~h}$. The sample was then placed into a programmed temperature control instrument including heating cell.
The temperature-dependent absorbance IR spectra were measured with Tensor 27 spectrometer, which was equipped with a deuterated $1-\alpha$-alanine doped triglycine sulfate (DLaTGS) detector. In order to avoid the oxidation of the poly(vinyl acetate) film sample, the sample was protected by dried highpurity nitrogen gas during measurement. Ninety-five IR spectra were collected from 10 to $200^{\circ} \mathrm{C}$ at about $2{ }^{\circ} \mathrm{C}$ increments and the temperature increasing rate was $5^{\circ} \mathrm{C} / \mathrm{min}$.

Before performing the $2 \mathrm{D}$ and MW2D correlation analysis, baseline correction and mean normalized (each IR spectrum was divided its intensity mean value) was applied. The software of 2D and MW2D was developed in our laboratory, were applied to processed and calculated. The theory of 2D and MW2D correlation spectroscopy has been described elsewhere 18-21,24,39. $^{\text {. }}$

\section{RESULTS AND DISCUSSION}

As shown in Fig. 1, complicated spectral variations are observed in the temperature-dependent IR spectra of poly(vinyl acetate) (not all displayed here). The prominent IR bands $\mathrm{O}-\mathrm{H}$ stretching modes (3500-3400 $\left.\mathrm{cm}^{-1}\right), \mathrm{C}-\mathrm{H}$ stretching vibration region (3100-2800 $\left.\mathrm{cm}^{-1}\right)$ and $\mathrm{C}=\mathrm{O}$ stretching bands $(1800-$ $\left.1650 \mathrm{~cm}^{-1}\right)$ are of interest to our study.

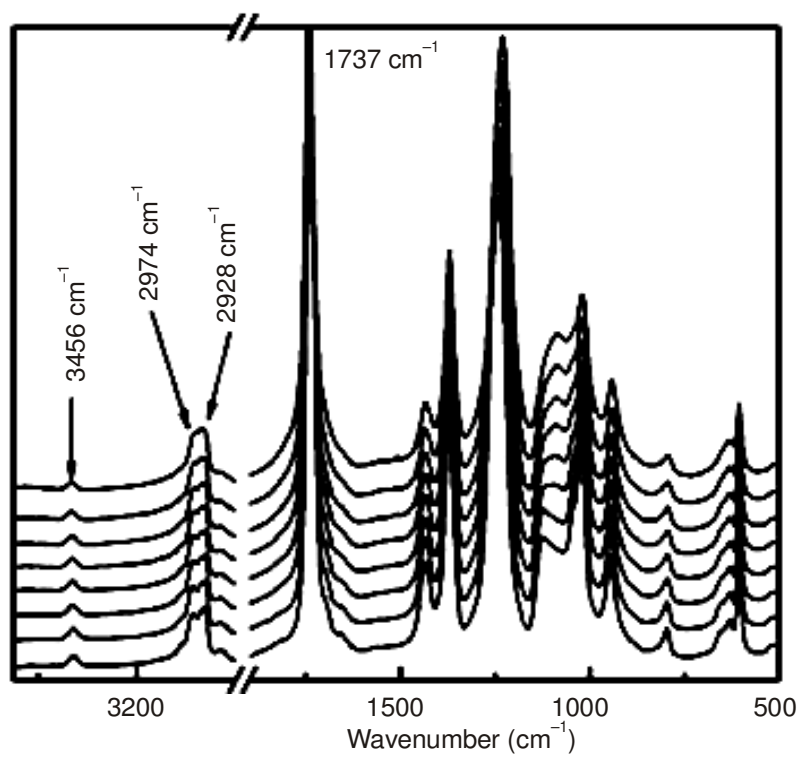

Fig. 1. Temperature-dependent IR spectra (not all displayed here) of poly(vinyl acetate) $\left(10-200{ }^{\circ} \mathrm{C}\right)$

O-H stretching region $\left(3500-3400 \mathrm{~cm}^{-1}\right)$ : Fig. 2a shows the 1D IR spectra of $\mathrm{OH}$ stretch bands in the region 3500-3400 $\mathrm{cm}^{-1}$ from 10 to $200{ }^{\circ} \mathrm{C}$. The obtained 1D IR spectra show only one small (it is really narrow) band at $3456 \mathrm{~cm}^{-1}$. This indicates poly(vinyl acetate) has only one kind of hydroxyl group. We can get more useful information from two-dimensional correlation infrared spectroscopy and moving-window two-dimensional correlation infrared spectroscopy. It is found that two correlation peaks shifting along the perturbation direction are clearly observed in the MW2D correlation map (Fig. 2b). Obviously, the bands at $3456 \mathrm{~cm}^{-1}$ is splitting into two bands. One is $3443 \mathrm{~cm}^{-1}$ and the other is $3475 \mathrm{~cm}^{-1}$, corresponding to the hydrogen-bonded hydroxyl groups and the free hydroxyl groups, respectively. It is well known that peak shift 
in the frequency range of the $\mathrm{X}-\mathrm{H}$ vibration is often used as a simplest and powerful spectroscopic criterion for the existence of $\mathrm{H}$-hydrogen bond ${ }^{13,14}$. This formation of hydrogen bond may be attributed to the interaction between the hydroxyl groups and the carbonyl groups of the poly(vinyl acetate). At $52{ }^{\circ} \mathrm{C}$, two positive correlation intensity peaks are obviously observed. It is obviously a consequence of the poly(vinyl acetate) glass transition. The glass transition of poly(vinyl acetate) by DSC measurement is $46{ }^{\circ} \mathrm{C}$ and this value is close to the result.

Fig. 2c, d shows synchronous and asynchronous 2D correlation spectra in the $3500-3400 \mathrm{~cm}^{-1}$ region calculated from the IR spectra in the temperature rang from 10 to $200{ }^{\circ} \mathrm{C}$. In this paper, blue and red areas in the $2 \mathrm{D}$ contour maps mark positive and negative correlation intensities, respectively. The synchronous spectra in Fig. 2c is dominated by two auto-peaks at about $3475,3443 \mathrm{~cm}^{-1}$, respectively. This result is consistent with the result of MW2D correlation analysis, which also shows two peaks along the perturbation direction (Fig. 2b). The negative cross-peaks at $(3475,3443) \mathrm{cm}^{-1}$ reveal that the direction of the bond intensity changes at $3475 \mathrm{~cm}^{-1}$ is opposite to that of the intensity changes at $3443 \mathrm{~cm}^{-1}$ with temperature increasing. It can well draw a conclusion that the intensity of hydrogen-bonded hydroxyl groups decreases and that of the free hydroxyl groups increase with temperature increasing.
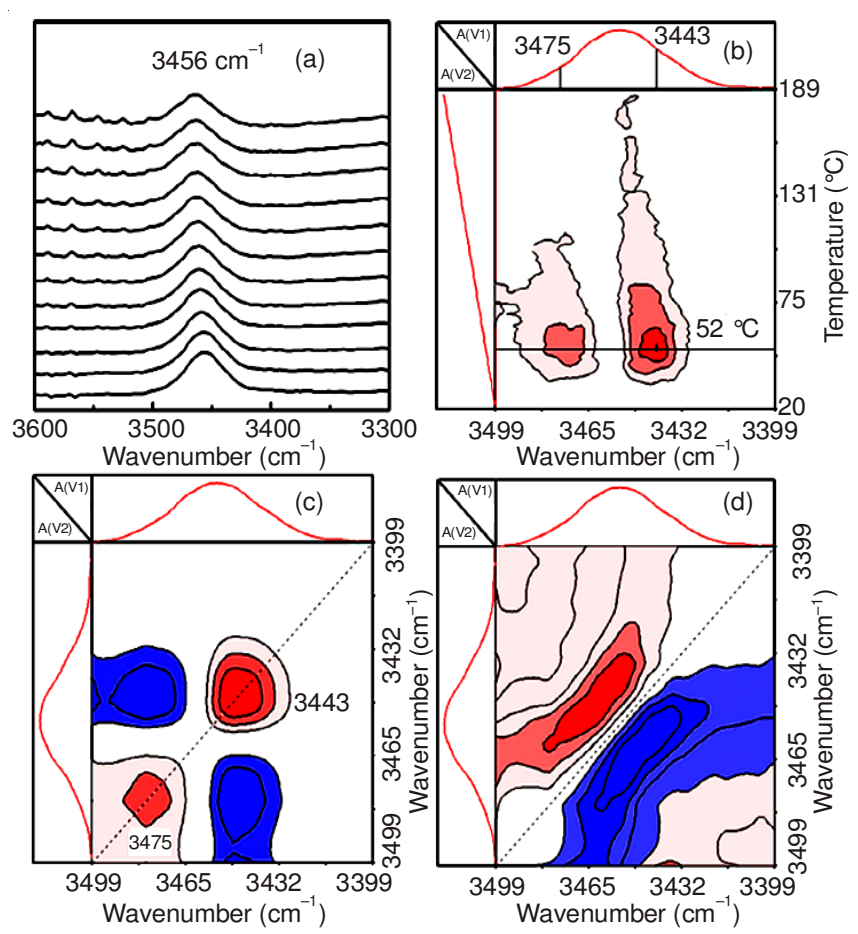

Fig. 2. Temperature- dependent IR spectra (not all displayed) (a), MW2D correlation spectrum (b), synchronous (c) and asynchronous 2D correlation spectrum (d) in the $3500-3400 \mathrm{~cm}^{-1}$ region of poly(vinyl acetate) $\left(10-200{ }^{\circ} \mathrm{C}\right)$

$\mathrm{C}=\mathbf{O}$ stretching region $\left(\mathbf{1 8 0 0}-\mathbf{1 6 5 0} \mathbf{c m}^{-1}\right)$ : Fig. 3a shows the temperature-dependent IR spectral of poly(vinyl acetate) in the $\mathrm{C}=\mathrm{O}$ stretching bands region. From the $1 \mathrm{D} I \mathrm{R}$, it is also difficult to get more information. Fig. $3 b$ shows the MW2D correlation spectrum based on autocorrelation calculations in the $1800-1650 \mathrm{~cm}^{-1}$ region. At $52{ }^{\circ} \mathrm{C}$, two positive correlation intensity peaks are obviously observed. Two correlation peaks shift along the perturbation direction is clearly found in the MW2D correlation map, which denotes the existence of $\mathrm{H}-$ hydrogen bond by the interaction between $\mathrm{C}=\mathrm{O}$ and $\mathrm{OH}$ in poly(vinyl acetate $)^{13,14}$.

Fig. 3c-d shows synchronous and asynchronous 2D correlation spectra in the $1800-1650 \mathrm{~cm}^{-1}$ region constructed from the IR spectra in the temperature range from 10 to $200{ }^{\circ} \mathrm{C}$. The synchronous spectra in Fig. $3 \mathrm{c}$ is dominated by two autopeaks at about $1756,1730 \mathrm{~cm}^{-1}$, respectively. This result is consistent with the result of MW2D correlation analysis, which also shows two peaks along spectral variable (Fig. 3b). From Fig. 3b, c, it can be well inferred here in poly(vinyl acetate) has at least two types of $\mathrm{C}=\mathrm{O}$. The negative cross-peaks at $(1756,1730) \mathrm{cm}^{-1}$ reveal that the direction of the bond intensity changes at $1756 \mathrm{~cm}^{-1}$ is opposite to that of the intensity changes at $1730 \mathrm{~cm}^{-1}$ with temperature increasing.

However, the corresponding asynchronous 2D correlation spectrum in Fig. 3d provides four deconvoluted bands at 1760, $1752,1733,1723 \mathrm{~cm}^{-1}$. Moreover, be similar to Zhang et al.' $s^{40}$ study, there is a so-called "butterfly pattern" in the $\mathrm{C}=\mathrm{O}$ stretching region in the asynchronous correlation spectra. Usually, the appearance of this pattern is attributed to a peak shift combined with the intensity changes or bands splitting ${ }^{41-44}$.
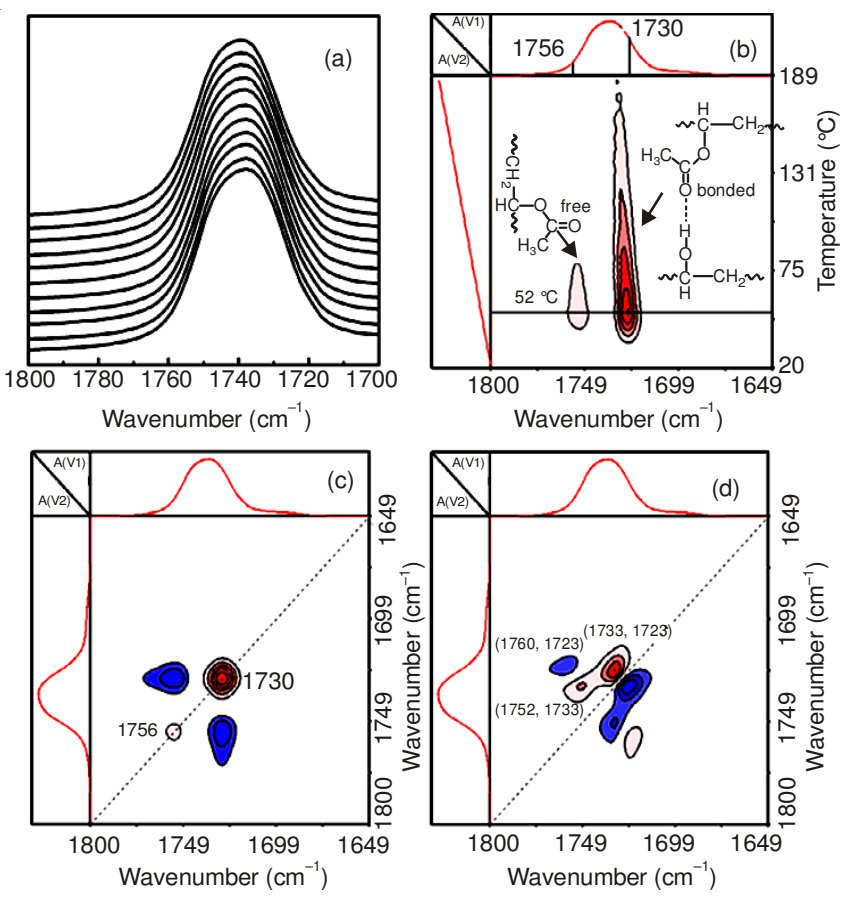

Fig. 3. Temperature-dependent IR spectra (not all displayed) (a), MW2D correlation spectrum (b), synchronous (c) and asynchronous 2D correlation spectrum (d) in the $1800-1650 \mathrm{~cm}^{-1}$ region calculated from temperature-dependent spectral variations of poly(vinyl acetate) between 10 and $200{ }^{\circ} \mathrm{C}$

These results demonstrate that the asynchronous spectrum is more powerful in the bonds deconvultion in comparison with synchronous spectrum. From above analysis, there have at least four types of $\mathrm{C}=\mathrm{O}$ in poly(vinyl acetate). Many previous studies have demonstrated that $\mathrm{C}=\mathrm{O}$ groups in crystalline polymers will spilt into two or three even more bands which 
contributes to the amorphous structure, or the highly ordered crystalline component, or the less ordered crystalline structure $^{25-29}$. However, it is well known that poly(vinyl acetate) is an amorphous polymer. Why the amorphous poly(vinyl acetate) have four types of $\mathrm{C}=\mathrm{O}$ ? There maybe the reason of hydrogen bond by the formation $\mathrm{C}=\mathrm{O}---\mathrm{H}-\mathrm{O}$. But it should have only two types of $\mathrm{C}=\mathrm{O}$ that one is free, the other is hydrogen bonded.

Galbiati et al..$^{45}$ measured the IR and Raman spectra of several aliphatic esters, namely of the series of $\mathrm{CH}_{3}-\mathrm{COO}$ $\left(\mathrm{CH}_{2}\right)_{\mathrm{n}} \mathrm{CH}_{3}(\mathrm{n}=0$ to 11$)$ in gas, liquid and solid phases. It was revealed that the observed frequencies of the $\mathrm{C}=\mathrm{O}$ stretching vibrations $\left(\mathrm{v}_{\mathrm{C}=\mathrm{O}}\right)$ of the compounds can be grouped into three wave number regions for the three phases: (1) $v_{\mathrm{C}=\mathrm{O}}>1760$ $\mathrm{cm}^{-1}$ for the gas phase, (2) $1750 \mathrm{~cm}^{-1}>v_{\mathrm{C}=0}>1740 \mathrm{~cm}^{-1}$ for the liquid phase and (3) $1730 \mathrm{~cm}^{-1}>v_{\mathrm{C}=\mathrm{O}}>1720 \mathrm{~cm}^{-1}$ for the solid phase. Because the poly(vinyl acetate) glass temperature in our system is only about $52^{\circ} \mathrm{C}$, we can safely inferred that the amorphous poly(vinyl acetate) probably transfers from solid phase to liquid phase by raising temperature from 10 to $200{ }^{\circ} \mathrm{C}$. May be the $\mathrm{C}=\mathrm{O}$ in different phase were clearly detected by asynchronous spectrum. In order to demonstrate the deduction, MW2D and 2D correlation spectra in the $1800-1650 \mathrm{~cm}^{-1}$ region are calculated from the IR spectra from 10 to $60^{\circ} \mathrm{C}$ and from 60 to $200^{\circ} \mathrm{C}$, respectively. From Fig. 4a,b and 5a,b, the corresponding MW2D and 2D synchronous correlation spectrum also show two major deconvoluted bands, which similar to Fig. 3a,b, although there is some difference at the values of peak wave numbers. But the asynchronous 2D correlation spectra in the $1800-1650 \mathrm{~cm}^{-1}$ region from 10 to $60{ }^{\circ} \mathrm{C}$ are much difference to that from 60 to $200{ }^{\circ} \mathrm{C}$.

Fig. $4 \mathrm{c}$ shows asynchronous $2 \mathrm{D}$ correlation spectra in the $1800-1650 \mathrm{~cm}^{-1}$ region in the temperature range from 10 to $60{ }^{\circ} \mathrm{C}$, which shows only one asynchronous cross peaks at $(1752,1728) \mathrm{cm}^{-1}$. According to the general rules proposed by Noda ${ }^{18-21}$, it reveals that $1752 \mathrm{~cm}^{-1}$ changes at first and then $1728 \mathrm{~cm}^{-1}$ with temperature increasing. Because the temperature is below $60{ }^{\circ} \mathrm{C}$, poly(vinyl acetate) is of solid phase. It can make a conclusion that $1752 \mathrm{~cm}^{-1}$ attributes to free $\mathrm{C}=\mathrm{O}$ stretching mode and $1728 \mathrm{~cm}^{-1}$ is due to hydrogen bonded $\mathrm{C}=\mathrm{O}$ structure in solid phase.
Fig. 5b,c shows synchronous and asynchronous 2D correlation spectra in the $1800-1650 \mathrm{~cm}^{-1}$ region constructed from the IR spectra in the temperature rang from 60 to $190^{\circ} \mathrm{C}$. The synchronous spectra in Fig. $5 \mathrm{~b}$ is dominated by two auto-peaks at about 1756, $1730 \mathrm{~cm}^{-1}$, respectively. The corresponding asynchronous $2 \mathrm{D}$ correlation spectrum in Fig. $5 \mathrm{c}$ provides four deconvoluted bands at 1762, 1753, 1733, $1724 \mathrm{~cm}^{-1}$. From above analysis, some poly(vinyl acetate) changes to liquid phase as temperature raises, so it can safely conclude that the band at $1762 \mathrm{~cm}^{-1}$ attribute to free bonded $\mathrm{C}=\mathrm{O}$ groups in liquid phase and $1753 \mathrm{~cm}^{-1}$ due to the free $\mathrm{C}=\mathrm{O}$ groups in solid phase, 1733 and $1724 \mathrm{~cm}^{-1}$ arise from the $\mathrm{C}=\mathrm{O}$ groups involved in the $\mathrm{C}=\mathrm{O}$ and $\mathrm{OH}$ interactions in liquid phase and solid phase, respectively. By Noda rules, it can also reveal that $1762 \mathrm{~cm}^{-1}$ (free bonded $\mathrm{C}=\mathrm{O}$ groups in liquid phase) takes place in prior to $1724 \mathrm{~cm}^{-1}$ (hydrogen bonded $\mathrm{C}=\mathrm{O}$ in solid phase) and 1753 $\mathrm{cm}^{-1}$ (non-interaction $\mathrm{C}=\mathrm{O}$ groups in solid phase), $1733 \mathrm{~cm}^{-1}$ (hydrogen bonded $\mathrm{C}=\mathrm{O}$ in liquid phase) take place in prior to 1753 and $1724 \mathrm{~cm}^{-1}$ (hydrogen bonded $\mathrm{C}=\mathrm{O}$ in solid phase) with temperature increasing.

Temperature-dependent changes in the $\mathrm{C}$-H stretching vibration region $\left(3100-2800 \mathrm{~cm}^{-1}\right)$ : The temperature-dependent changes in the IR spectra of poly(vinyl acetate) in the $3100-2800 \mathrm{~cm}^{-1}$ region are shown in Fig. 6a. For the C-H stretching vibration region, bands at 2932 and $2862 \mathrm{~cm}^{-1}$ are ascribed to $\mathrm{O}-\mathrm{CH}_{3}$ (ester group) asymmetric stretching and symmetric stretching vibrations, respectively. That appeared around 2970 $\mathrm{cm}^{-1}$ is attributed to the $\mathrm{CH}_{2}$ antisymmetric stretching vibration. The vibrational bands observed at $3020 \mathrm{~cm}^{-1}$ is due to $\mathrm{C}=\mathrm{CH}$ antisymmetric stretching vibration. Fig. $6 \mathrm{~b}, \mathrm{c}$ illustrate the synchronous and asynchronous $2 \mathrm{D}$ correlation spectra in the $3020-2800 \mathrm{~cm}^{-1}$ region constructed from the temperaturedependent IR spectra. Five autopeaks are clearly observed at 3020, 2990, 2957, 2903 and $2851 \mathrm{~cm}^{-1}$ in the synchronous map. The bands at 2990, $2957 \mathrm{~cm}^{-1}$ are assigned to $\mathrm{CH}_{2}$ and $\mathrm{CH}_{3}$ asymmetric stretching modes, respectively, although the frequency of them in synchronous correlation spectra has a difference to that in the 1D IR spectra of poly(vinyl acetate). A new band at $2903 \mathrm{~cm}^{-1}$ is due to $\mathrm{CH}$ asymmetric stretching. The strong auto-peaks at 2990 and $2957 \mathrm{~cm}^{-1}$ indicate the significant temperature-dependent intensity variation of the
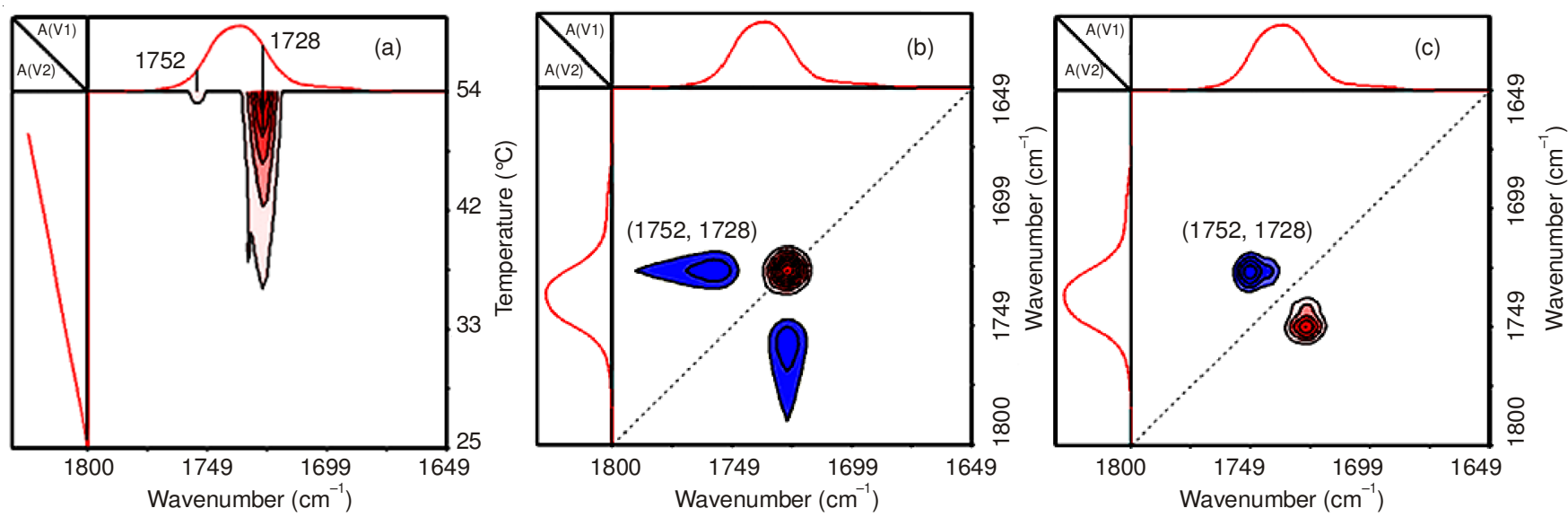

Fig. 4. MW2D correlation spectrum (a), synchronous (b) and asynchronous 2D correlation spectrum (c) in the $1800-1650 \mathrm{~cm}^{-1} \mathrm{region}$ calculated from temperature-dependent spectral variations of poly(vinyl acetate) between 10 and $60{ }^{\circ} \mathrm{C}$ 

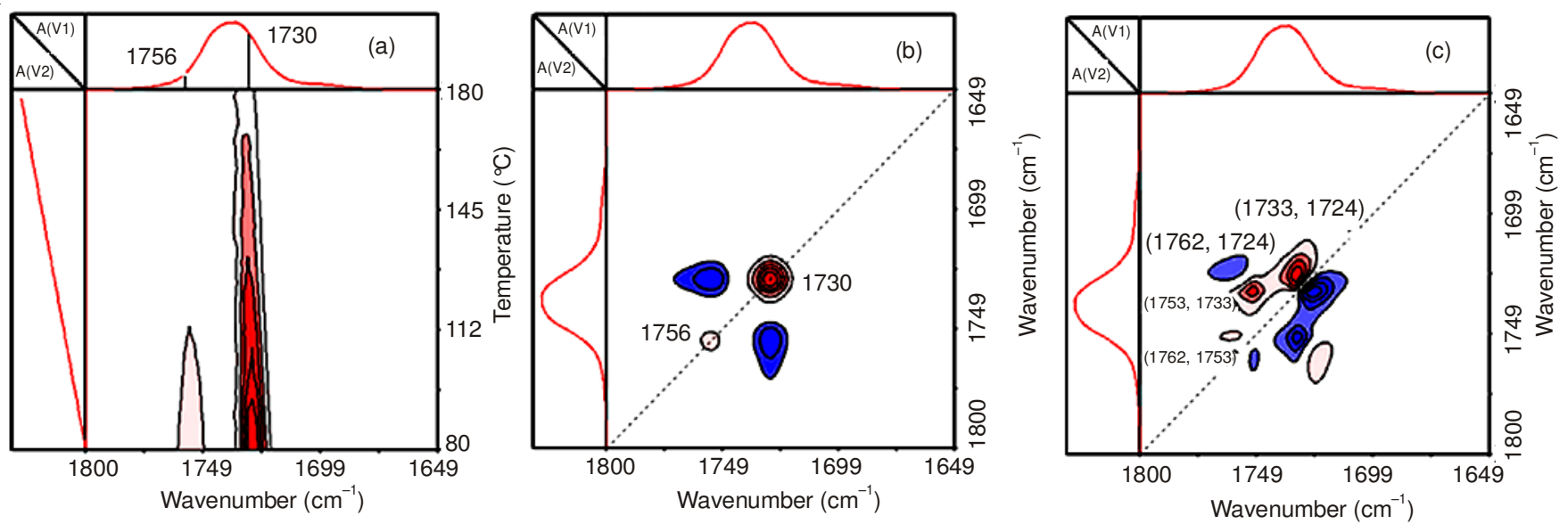

Fig. 5. MW2D correlation spectrum (a), synchronous (b) and asynchronous 2D correlation spectrum (c) in the 1800-1650 $\mathrm{cm}^{-1}$ region calculated from temperature-dependent spectral variations of poly(vinyl acetate) between $60^{\circ} \mathrm{C}$ and $190^{\circ} \mathrm{C}$
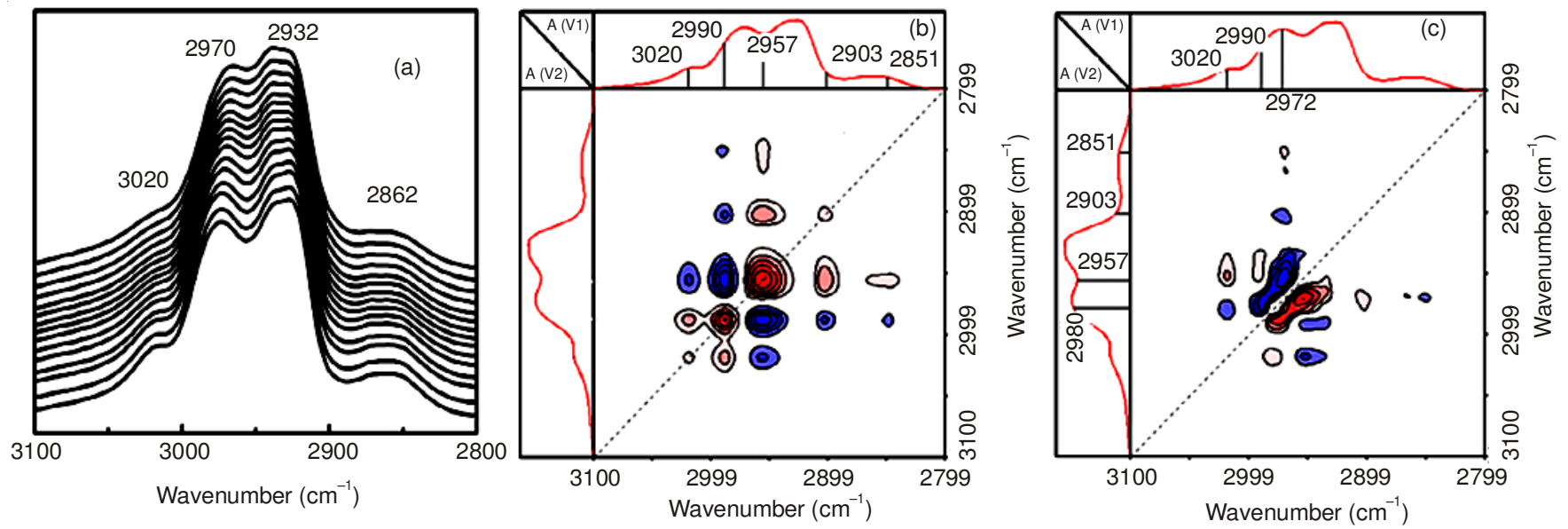

Fig. 6. Temperature- dependent IR spectra (not all displayed) (a), synchronous (b) and asynchronous $2 \mathrm{D}$ correlation spectrum (c) in the $3100-2800 \mathrm{~cm}^{-1}$ region calculated from temperature-dependent spectral variations of poly(vinyl acetate) between 10 and $200{ }^{\circ} \mathrm{C}$

hydrocarbon chains. Three positive cross-peaks are observed at (3020 versus 2990), (2957 versus 2851 and 2903) $\mathrm{cm}^{-1}$ and four negative cross-peaks are detected at (3020, 2957), (2990 versus 2957, 2903 and 2851) $\mathrm{cm}^{-1}$ on the left up side of the synchronous correlation spectra. According to Node's rule, it is suggested that $\mathrm{HC}=\mathrm{CH}$ and $\mathrm{CH}_{2}, \mathrm{CH}_{3}$ and $\mathrm{CH}$ have the same orientation behaviors, but $\mathrm{HC}=\mathrm{CH}, \mathrm{CH}_{2}$ and $\mathrm{CH}_{3}, \mathrm{CH}$ show different orientation behaviors as temperature increase from 10 and $200^{\circ} \mathrm{C}$. Fig. 7 gives the frequency changes of two vibrational modes as a function of temperature, these two bands can be assigned to the stretching modes of the $\mathrm{CH}_{2}$ and $\mathrm{CH}_{3}$, respectively. Obviously, with temperature increasing, the $\mathrm{CH}_{2}$ stretching mode shift to lower frequency. However, the $\mathrm{CH}_{3}$ stretching mode shifts to higher vibration frequency. The result confirms that $\mathrm{CH}_{2}$ and $\mathrm{CH}_{3}$ have different orientation behaviors as temperature increases.

The asynchronous correlation spectra have excellent deconvolution ability. It should be noticed that two new bands at 2972 and $2980 \mathrm{~cm}^{-1}$ are identified. As the group of $\mathrm{HC}=\mathrm{CH}$ exists in the main chain of poly(vinyl acetate), there is more than one types of $\mathrm{CH}_{2}$ in poly(vinyl acetate). The bands at 2972 and $2980 \mathrm{~cm}^{-1}$ are also assigned to $\mathrm{CH}_{2}$ asymmetric stretching modes. Accord to the rules proposed by Noda, the sequential order of bands changes is: $2957>2990,2972>$ 3020 and $2903>2990,2972>3020 \mathrm{~cm}^{-1}$. This sequence means

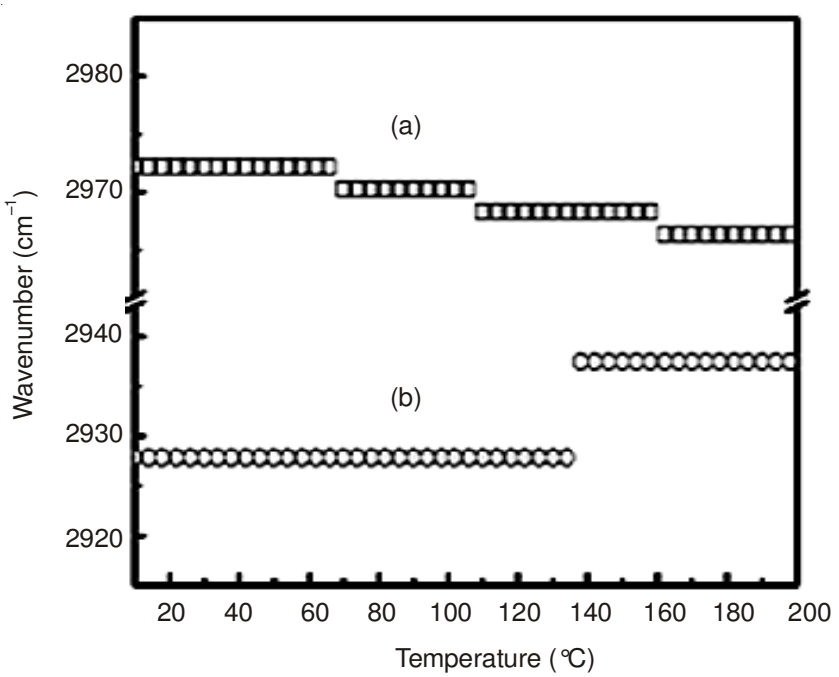

Fig. 7. Temperature dependences of the frequency of $\mathrm{CH}_{2}$ (a) and $\mathrm{CH}_{3}$ (b) of stretching modes in poly(vinyl acetate)

$\mathrm{CH}_{3}$ or $\mathrm{CH}$ group changed its movement first and then $\mathrm{CH}_{2}$ group and $\mathrm{HC}=\mathrm{CH}$ group following. Thus, we can conclude that, along with the temperature increasing in $10-200{ }^{\circ} \mathrm{C}$ regions, the side chain takes place prior to major chain. The sketch of chemical structure and the sequence of groups' movements are shown in Fig. 8. The results of 2D correlation 
spectra of poly(vinyl acetate) in the $3100-2800 \mathrm{~cm}^{-1}$ region from 60 and $200{ }^{\circ} \mathrm{C}$ are similar to Fig. 6, but the relative intensity of autopeaks has slightly difference.

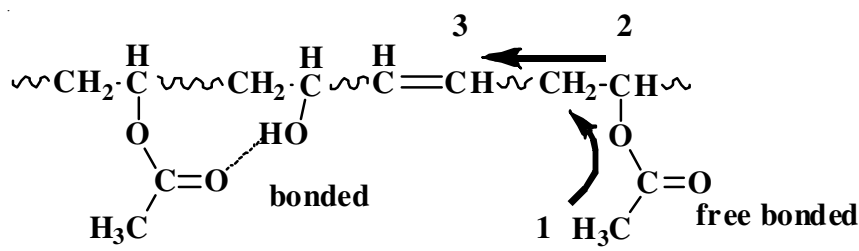

Fig. 8. Sketch of chemical structure and the sequence of groups' movements of poly(vinyl acetate)

\section{Conclusion}

The chemical structure and structure changes of poly(vinyl acetate) were investigated using MW2D and 2D IR correlation spectroscopy. The glass transition of poly(vinyl acetate) by MW2D correlation spectroscopy is determined at $52^{\circ} \mathrm{C}$, which is close to the value measured by DSC measurement. In the $3500-3400$ and $1800-1650 \mathrm{~cm}^{-1}$ region, two correlation peaks are clearly observed in MW2D and synchronous 2D correlation map. Furthermore, they shift along the perturbation direction in the MW2D correlation map. The results denote the existence of $\mathrm{H}$-hydrogen bond with the interaction between $\mathrm{C}=\mathrm{O}$ and $\mathrm{OH}$ in poly(vinyl acetate).

The $\mathrm{C}=\mathrm{O}$ in different phase were clearly detected by asynchronous spectrum as poly(vinyl acetate) transfers from solid phase to liquid phase by raising temperature from 10 to $200{ }^{\circ} \mathrm{C}$. Four deconvoluted bands at 1762, 1753, 1733, 1724 $\mathrm{cm}^{-1}$ were detected by the asynchronous $2 \mathrm{D}$ correlation spectrum. The bands at $1762 \mathrm{~cm}^{-1}$ arise from free bonded $\mathrm{C}=\mathrm{O}$ groups in liquid phase and $1753 \mathrm{~cm}^{-1}$ due to the free or noninteraction $\mathrm{C}=\mathrm{O}$ groups in solid phase. 1733 and $1724 \mathrm{~cm}^{-1}$ attribute to the $\mathrm{C}=\mathrm{O}$ groups involved in the $\mathrm{C}=\mathrm{O}$ and $\mathrm{OH}$ interactions in liquid phase and solid phase. It can also be revealed that the sequential order of bands changes is: 1762 $\mathrm{cm}^{-1}$ (free bonded $\mathrm{C}=\mathrm{O}$ groups in liquid phase) $>1724 \mathrm{~cm}^{-1}$ (hydrogen bonded $\mathrm{C}=\mathrm{O}$ in solid phase), $1753 \mathrm{~cm}^{-1}$ (non-interaction $\mathrm{C}=\mathrm{O}$ groups in solid phase) and $1733 \mathrm{~cm}-1$ (hydrogen bonded $\mathrm{C}=\mathrm{O}$ in liquid phase) $>1753,1724 \mathrm{~cm}^{-1}$.

In the $3100-2800 \mathrm{~cm}^{-1}$ region, seven bands are identified at $3020,2990,2980,2972,2957,2903$ and $2851 \mathrm{~cm}^{-1}$ by 2D correlation spectrum. The bands at 2990, 2980 and $2972 \mathrm{~cm}^{-1}$ are ascribed to $\mathrm{CH}_{2}$ in different structure environments as the group of $\mathrm{HC}=\mathrm{CH}\left(3020 \mathrm{~cm}^{-1}\right)$ exists in the main chain of poly(vinyl acetate). The bands at 2957 and $2851 \mathrm{~cm}^{-1}$ attribute to $\mathrm{O}-\mathrm{CH}_{3}$ (ester group) asymmetric stretching and symmetric stretching vibrations, respectively. The band at $2903 \mathrm{~cm}^{-1}$ is due to $\mathrm{CH}$ asymmetric stretching. The intensity of bands changes in the following sequence with temperature: $2957>$ $2990,2972>3020$ and $2903>2990,2972>3020 \mathrm{~cm}^{-1}$, which denotes that the side chain takes place prior to major chains.

\section{REFERENCES}

1. E. El Shafee, Polymer, 43, 921 (2002).

2. S.W. Kuo, S.C. Chan and F.C. Chang, Polymer, 43, 3653 (2002).
3. M.W. Huang, S.W. Kuo and H.D. Wu, Polymer, 43, 2479 (2002).

4. G. Sivalingam, R. Karthik and Giridhar Madras, Polym. Degrad. Stab., 84, 345 (2004).

5. D.E. Bhagwagar, C.J. Serman, P.C. Painter and M.M. Coleman, Macromolecules, 22, 4654 (1989).

6. S. Viswanathan and M.D. Dadmun, Macromolecules, 36, 3196 (2003).

7. S.W. Kuo and F.C. Chang, J. Polym. Sci. B, Polym. Phys., 40, 1661 (2002).

8. S. Viswanathan and M.D. Dadmun, Macromolecules, 35, 5049 (2002).

9. S.W. Kuo and F.C. Chang, Macromolecules, 34, 7737 (2001).

10. G.A. Jeffrey, An Introduction to Hydrogen Bonding, Oxford University Press: New York (1997).

11. G.R. Desiraju and T. Steiner, The Weak Hydrogen Bond, Oxford University Press: Oxford (1999).

12. S. Scheiner, Hydrogen Bonding, Oxford University Press: New York (1997).

13. A.D. Buckingham, J.E. Del Bene and S.A.C. McDowell, Chem. Phys. Lett., 463, 1 (2008).

14. P. Hobza and Z. Havlas, Chem. Rev., 100, 4253 (2000).

15. S. Selvasekarapandian, R. Baskaran, O. Kamishima, J. Kawamura and T. Hattori, Spectrochim. Acta A, 65, 1234 (2006).

16. J.H. Sung, S.J. Park, J.H. Park, H.J. Choi and J.S. Choi, Synth. Met., 156, 861 (2006).

17. N.G. Wen, Q.Q. Tang, M. Chen and L.M. Wu, J. Colloid Interf. Sci., 320, 152 (2008).

18. I. Noda, Bull. Am. Phys. Soc., 31, 520 (1986).

19. I. Noda, Appl. Spectrosc., 47, 1329 (1993).

20. I. Noda, J. Am. Chem. Soc., 111, 8116 (1989).

21. I. Noda, A.E. Dowrey, C. Marcoli, G.M. Story and Y. Ozaki, Appl. Spectrosc., 54, 236 (2000).

22. J. Zhang, Y. Duan, D. Shen, S. Yan, I. Noda and Y. Ozaki, Macromolecules, 37, 3292 (2004).

23. M. Thomas and H.H. Richardson, Vib. Spectrosc., 24, 137 (2000).

24. T. Zhou, A.M. Zhang, C.S. Zhao, H. Liang, Z. Wu and J. Xia, Macromolecules, 40, 9009 (2007).

25. A. Padermshoke, Y. Katsumoto, H. Sato, S. Ekgasit, I. Noda and Y. Ozaki, Spectrochim. Acta A, 61, 541 (2005).

26. A. Padermshoke, H. Sato, Y. Katsumoto, S. Ekgasit, I. Noda and Y. Ozaki, Polymer, 45, 7159 (2004).

27. J.M. Zhang, H. Sato, H. Tsuji, I. Noda and Y. Ozaki, Macromolecules, 38, 1822 (2005).

28. H.J. Jiang, P.Y. Wu and Y.L. Yang, Biomacromolecules, 4, 1343 (2003).

29. H.H. Zhang, Y.Q. Wu, B.L. Bai and M. Li, Spectrochim. Acta A, 63, 117 (2006).

30. R. Svoboda, P. Pustková and J. Málek, Polymer, 49, 3176 (2008).

31. L.C.E. Struik, Polymer, 38, 5233 (1997).

32. G.B. McKenna, M.G. Vangel, A.L. Rukhin, S.D. Leigh, B. Lotz and C. Straupe, Polymer, 40, 5183 (1999).

33. E. Donth and E. Hempel, J. Non-Cryst. Solids, 306, 76 (2002).

34. A. Aharoune, P. Marceron-Balland and C. Cunat, Mech. Time-Depend. Mater., 5, 345 (2001).

35. M. Delin, R.W. Rychwalski, J. Kubát, C. Klason and J.M. Hutchinson, Polym. Eng. Sci., 36, 2955 (1996).

36. J.M.G. Cowie, S. Harris and I.J. McEwen, Macromolecules, 31, 2611 (1998).

37. J.E. McKinney and M. Goldstein, J. Res. Natl. Bur. Stand A, 78A, 331 (1974).

38. J.M. Hutchinson and P. Kumar, Thermochim. Acta, 391, 197 (2002).

39. S. Morita, H. Shinzawa, R. Tsenkova, I. Noda and Y.J. Ozaki, Mol. Struct., 799, 111 (2006).

40. J.M. Zhang, H. Tsuji, I. Noda and Y. Ozaki, Macromolecules, 37, 6433 (2004).

41. M.A. Czarnecki, Appl. Spectrosc., 52, 1583 (1998).

42. M.A. Czarnecki, Appl. Spectrosc., 54, 986 (2000).

43. J. Yu and P.Y. Wu, Polymer, 48, 3477 (2007).

44. S. Morita, H. Shinzawa, I. Noda and Y. Ozaki, J. Mol. Struct., 799, 16 (2006).

45. E. Galbiati, M.D. Zoppo, G. Tieghi and G. Zerbi, Polymer, 34, 1806 (1993). 